\title{
BMJ Open Gaps in health behaviours and use of preventive services between patients with diabetes and the general population: a population-based cross- sectional study
}

\author{
Hyun-Young Shin, ${ }^{1}$ Sohee Park, ${ }^{2}$ Sang Min Park ${ }^{3}$
}

To cite: Shin H-Y, Park S, Park SM. Gaps in health behaviours and use of preventive services between patients with diabetes and the general population: a population-based crosssectional study. BMJ Open 2018;8:e017937. doi:10.1136/ bmjopen-2017-017937

- Prepublication history for this paper is available online. To view these files, please visit the journal online (http://dx.doi. org/10.1136/bmjopen-2017017937).

Received 26 May 2017 Revised 20 April 2018 Accepted 24 May 2018
Check for updates

${ }^{1}$ Department of Family Medicine, Myongji Hospital, Seoul, The Republic of Korea

${ }^{2}$ Department of Biostatistics, Graduate School of Public Health, Yonsei University, Seoul, The Republic of Korea ${ }^{3}$ Department of Family Medicine, Seoul National University Hospital, Seoul National University College of Medicine, Seoul, The Republic of Korea

Correspondence to Dr Sang Min Park smpark.snuh@gmail.com

\section{ABSTRACT}

Objectives Although both the prevalence and treatment rate of diabetes have increased, the degree of adherence to healthy behaviours by patients with diabetes has not yet been comprehensively evaluated. This study examines the differences in health management and mental health status according to diabetes status and awareness of that diagnosis.

Methods This was a cross-sectional study of 14655 people using data from the Korean National Health and Nutrition Examination Study 2010-2012, which used sampling weights. Multiple logistic regression analyses were used to compare health-risk behaviours, preventive healthcare utilisation and mental health status according to diabetes diagnosis and awareness of the disease.

Results Compared with people without diabetes, people with diabetes had comparably worse smoking status (adjusted OR (aOR) 1.09, 95\% Cl 0.92 to 1.30), insufficient physical activity (aOR 1.09, 95\% Cl 0.95 to 1.24) and were less likely to receive cancer screenings and regular health check-ups (aOR $0.75,95 \% \mathrm{Cl} 0.66$ to 0.85). Furthermore, compared with people unaware of their diabetes, people aware of their diabetes had lower odds of physical inactivity (aOR $0.66,95 \% \mathrm{Cl} 0.45$ to 0.99 ) and greater odds of receiving colon cancer screening (aOR $1.55,95 \% \mathrm{Cl}$ 1.17 to 2.05 ) and influenza vaccination (aOR $1.56,95 \% \mathrm{Cl}$ 1.15 to 2.11).

Conclusions People with diabetes were no better in terms of health behaviours and preventive healthcare utilisation than those who were without diabetes. Further efforts and political attention to ensure the delivery of quality care for people with diabetes are needed.

\section{INTRODUCTION}

Diabetes is a major non-communicable disease and its prevalence has increased worldwide. ${ }^{1}$ Diabetes has numerous complications and comorbidities, ${ }^{2}$ which means that its appropriate management, in particular through maintenance of healthy behaviours, is important for patients' long-term healthcare. Smoking is a major modifiable risk factor for type 2 diabetes and is related to diabetes
Strengths and limitations of this study

- This is the first study to examine differences in health-related factors between those who are aware of their diabetes and those who are unaware of their diabetes.

- We analysed data from a National Health Survey with sampling weights.

- The cross-sectional design and possible recall bias are the main limitations of this study.

- The study sample had relatively mild diabetes because people admitted to a hospital or nursing home were not included in the Korean National Health and Nutrition Examination Survey.

incidence, complications and mortality, ${ }^{3-7}$ and alcohol use may interfere with glucose control or induce hypoglycaemia in people with diabetes. ${ }^{8-10}$ Sedentary lifestyle is a risk factor for death in those with diabetes, and physical activity is important for achieving glucose control and decreasing insulin resistance, which can prevent type 2 diabetes and its complications. ${ }^{11}$ Furthermore, regular cancer screening is exceedingly important for people with diabetes because diabetes is associated with cancers of the liver, biliary tract, pancreas, oesophagus, kidneys, colon, endometrium and breast. ${ }^{12}$ However, several reports have showed that patients with diabetes tend to pay rather little attention to diabetes care management and do not engage in health behaviours regularly. ${ }^{13-17}$ Moreover, patients with diabetes tend to suffer more from mental health problems, which can negatively affect their practice of healthy behaviours. ${ }^{18-21}$

In 2016, the prevalence of diabetes in South Korea reached upwards of $13.7 \%$, while the rates of awareness and treatment of diabetes were $70.7 \%$ and $89.2 \%$, respectively. ${ }^{2}$ While 
the treatment rate has increased compared with previous years, the rate does not clearly indicate Korean patients' adherence to healthy behaviours. Because the national health insurance system does not provide coverage for diabetes education for healthy behaviour enough, diagnosis and treatment of diabetes receive attention in the medical field in Korea. Therefore, our hypothesis was that health behaviours of those with diabetes is not better than that of those without diabetes. Understanding the participation of patients with diabetes in health behaviours and preventive healthcare utilisation could be helpful for improving their care management. In addition, knowing discrepancies in health behaviours between individuals with diagnosed and undiagnosed diabetes might help in understanding the current status of health behaviour education and the state of monitoring systems within medical facilities throughout South Korea. Therefore, this study examined health-risk behaviours, preventive healthcare utilisation and mental health statuses according to the presence and awareness of diabetes in South Korea using nationally representative data.

\section{METHODS}

This study is based on the Korean National Health and Nutrition Examination Survey (KNHANES), which is conducted by the Korean Ministry of Health and Welfare. The KNHANES is a nationwide representative study, of which, to date, six waves have been conducted: I (1998), II (2001), III (2005), IV (2007-2009), V (2010-2012) and VI (2013-2015). This survey used a stratified, multistage probability sampling design to select household units. To represent the entire Korean adult population and account for the complex sampling procedure, sampling weights were used. This included stratification by district in the first step and stratification by gender and age in the second step. The survey comprised the following: the Health Interview Survey, Health Behaviour Survey, Nutrition Survey and Health Examination Survey. All individuals were evaluated using self-administered questionnaires; interviewers could assist participants who had difficulties in completing the questionnaire themselves. Written informed consent for using their data in further analyses was provided by all participants, and they were all given the option of exercising their right to refuse to participate in accordance with the National Health Enhancement Act.

\section{Participants}

We focused on the cross-sectional data of 25534 people who participated in the KNHANES V(2010-2012), using the data from the Health Interview Survey and Health Examination Survey. Of the total population, we excluded 8242 participants under 30 years old and 2637 who had essential data missing-for example, information on diabetes and their awareness of diabetes diagnosis. For the final study group, 14655 people (6272 men and 8383 women) were ultimately included in the analyses. All the results were sent to the participants so that they can follow up the abnormal findings of the test.

\section{Blood collection and biochemical analyses}

For clinical chemistry assays, serum was obtained from each participant via separation from peripheral venous blood collected after a minimum fasting period of 8 hours. Fasting glucose and haemoglobin Alc (HbAlc) levels were measured by high-performance liquid chromatography on a Tosoh G8 device (Tosoh, Tokyo, Japan).

\section{Classification of socioeconomic status and health-risk behaviours}

The self-administered questionnaire of the Health Interview Survey was used to obtain information on socioeconomic factors (ie, age, gender, education level, employment status, marital status and household monthly income), health-related factors (ie, smoking status, alcohol use, physical activity and mental health status) and preventive healthcare utilisation (ie, cancer screening participation, regular health check-ups in the past 2 years and influenza vaccination). Education level was classified as 'college or higher', 'high school' and 'middle school or lower'. Employment status was divided into 'non-manual', 'manual' and 'others' (including students, homemakers and those with no occupation). Marital status was divided into 'married' and 'others' (which included 'single' and 'divorced/separated/widowed'). Household income was categorised into quartiles reflecting 'low', 'low middle', 'middle high' and 'high' income.

Smoking status was categorised into 'current smoker' and 'past/non-smoker' (including ex-smoker and neversmoker). The 'current smoker' category included those who smoked regularly or intermittently as of the time of survey administration. 'Alcohol consumption' was assessed by asking the question, 'How many drinks of alcohol do you have at one time?' Participants' answers were categorised into two groups according to the amount of drinking; having two or fewer drinks for men and one drink or less for women indicated a 'non-drinker', and others were classified as 'drinkers'. Physical inactivity was assessed using a questionnaire based on the International Physical Activity Questionnaire (IPAQ) short form. ${ }^{22}$ No physical activity' was defined as not engaging in any combination of walking, moderate-intensity or vigorous-intensity activities in the last week; 'insufficient physical activity' was defined as reporting some activity, but not enough to meet the requirements for category 2 (moderate) or 3 (high) physical activity levels on the IPAQ and finally, 'sufficient physical activity', which was used as a reference in the analysis, was considered as meeting the requirements for either category 2 (moderate) or 3 (high) physical activity levels. More details are provided in the IPAQ guidelines. ${ }^{23}$ Body weight and height were measured to the nearest $0.1 \mathrm{~kg}$ and $0.1 \mathrm{~cm}$, respectively, while participants were wearing light indoor clothes without shoes. Body mass index (BMI) was calculated 
as the ratio of weight in kilograms to squared height in metres $\left(\mathrm{kg} / \mathrm{m}^{2}\right)$.

\section{Measurement of preventive healthcare utilisation and mental health status}

Preventive healthcare utilisation was assessed in terms of health check-ups, cancer screening and influenza vaccination in the self-administered questionnaires. In South Korea, there are several types of free health check-ups, depending on the individual's age, which are provided by the National Health Insurance Organisation. General health check-ups are available to all people over 40 years of age every 2 years, and include blood tests to assess haemoglobin, fasting glucose and lipid profile; liver and kidney function tests; oral examinations; chest $\mathrm{X}$-rays and dementia screening tests. As for cancer screening, National Cancer Screening Programmes are freely provided for five major cancers, including uterine cervical cancer (for women aged over 30 years), breast cancer (for women aged over 40 years), gastric cancer (for all individuals aged over 40 years), colorectal cancer (for individuals aged over 50 years) and liver cancer (for high-risk individuals aged over 40 years). ${ }^{24}$ In this study, cancer screening data were obtained for cervical, breast, gastric and colon cancer. The screening methods used were as follows: for uterine cervical cancer, biennial pap smear tests; for breast cancer, biennial mammography with palpation; for gastric cancer, biennial gastric endoscopy or upper gastrointestinal series and for colorectal cancer, annual faecal occult blood tests. ${ }^{25}$ To assess whether participants had undergone cancer screening, they were asked 'Have you received cancer screening within the last 2 years?' Participants also answered a question concerning health check-ups: 'Have you undergone a health check-up within the last 2 years?' Influenza vaccination status was assessed by asking 'Have you received influenza vaccination during the past year?' All of the questions were answered with 'yes' or 'no'.

Depression symptoms were evaluated by asking participants, 'Have you felt sad, unhappy or desperate for more than 2 weeks, to the point that it interfered with your daily activities, during the past year?' Suicidal thoughts were identified by asking, 'Have you thought of killing yourself during the past year?' Finally, suicide attempts were assessed by asking, 'Have you tried to kill yourself during the past year?' All these questions were answered with 'yes' or 'no'.

\section{Definition of diabetes status and awareness of diabetes}

Diabetes mellitus was defined as having a serum fasting blood glucose level $\geq 126 \mathrm{mg} / \mathrm{dL}$, taking medication (oral drugs or insulin) for diabetes, or having an HbAlc $\geq 6.5 .{ }^{24}$ Among the people who met the criteria of diabetes above, participants' awareness of a diagnosis of diabetes was assessed by asking this question, 'Have you been diagnosed with diabetes by a doctor?' Participants who answered 'yes' were considered to be aware of the fact that they had diabetes, and thus were included in the 'aware group'; conversely, those who answered 'no' were included in the 'unaware group'. Patients who did not meet any of the criteria for diabetes were allocated to the 'no diabetes group' or 'without diabetes group'. A schematic of the study design is depicted in figure 1 .

\section{Statistical analysis}

Statistical analyses were performed according to the presence and awareness of diabetes. As noted above, in order to represent the entire Korean adult population without
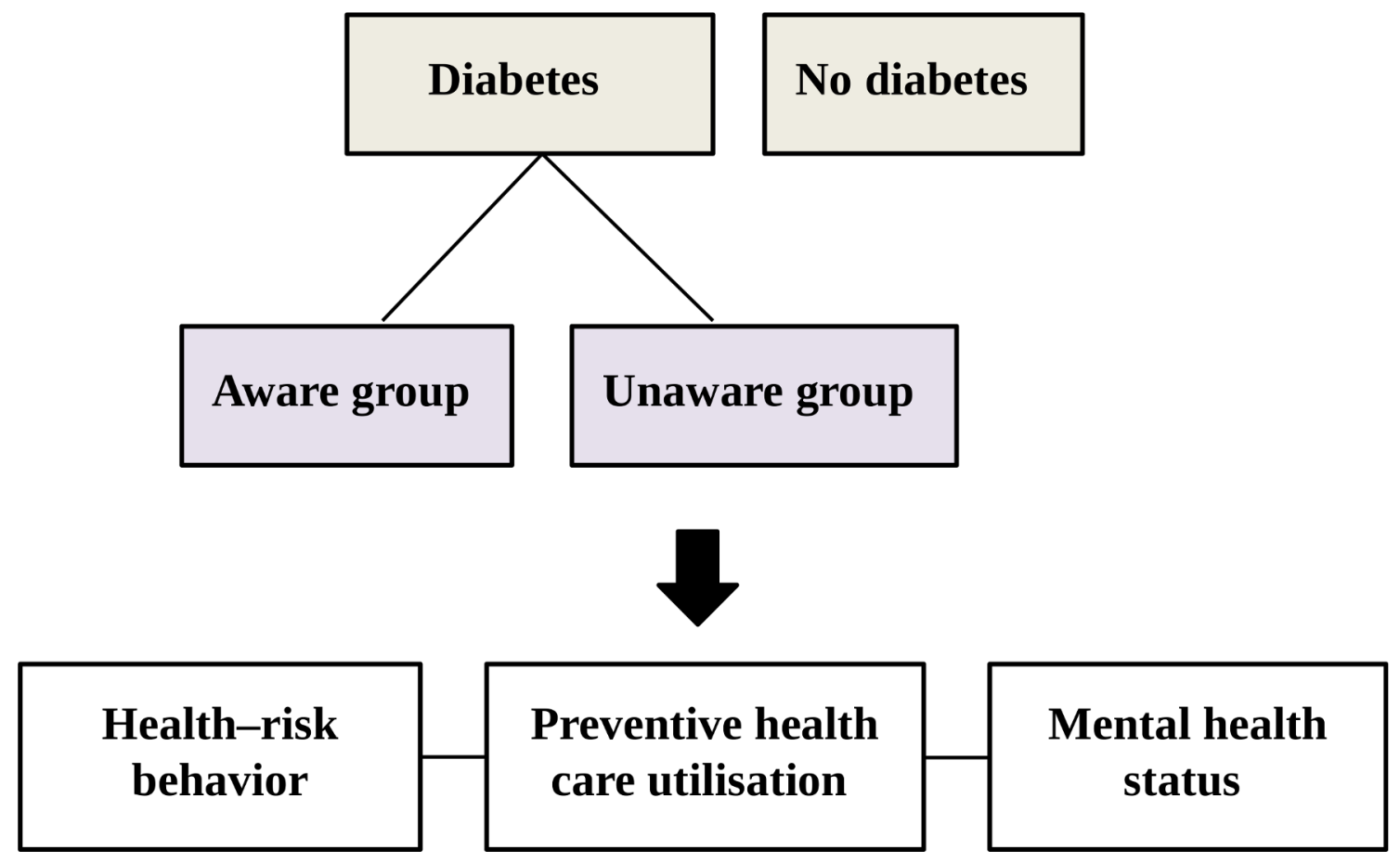

Figure 1 Schematic of the study design. 
biased estimates and account for the complex sampling design, sampling weights were applied (including stratification by district at the first step). Multinomial logistics regression analyses were performed to evaluate the association of diabetes or its awareness with physical activities.

Multiple logistic regression analyses were used to examine how health-related behaviours, preventive healthcare utilisation and mental health status were influenced in two groups of those with and without diabetes. The same analyses were applied to the diabetes group according to its awareness of diabetes diagnosis. Adjusted ORs were calculated adjusting for age, gender and BMI in model 1 and model 1 plus education level, employment status, self-rated health status, medical insurance and house income level in model 2. Final optimal model for multivariate regression analysis was identified through several steps as follows. First, univariate analyses were done to select statistically significant factors $(p>0.15)$ with diabetes awareness. Second, hierarchical selection was performed through C-statistics and Mosmer-Lemeshow test. Third, clinically important confounding factors were added to the final model. All analyses were conducted using SAS V.9.2 (SAS Institute). All statistical tests were two sided and statistical significance was indicated by $\mathrm{p}<0.05$.

\section{Patient and public involvement}

The Korean National Health and Nutrition Survey used in this study is nationwide data, which is collected annually by the Korea Centers for Disease Control and Prevention (KCDC) and is open to researchers. All the results were sent to the participants so that they can follow up the abnormal findings of the test. In addition, if the critical value including an emergency or serious abnormality is detected, the individual is notified within 24 hours from the KCDC.

\section{RESULTS}

The descriptive characteristics of three groups are shown in table 1. Among the 14655 participants, 12750 (87.0\%), $612(4.2 \%)$ and $1293(8.8 \%)$ were in the no diabetes, unaware and aware groups, respectively.

As shown in table 2, compared with participants without diabetes, those in the diabetes group had greater odds of current smoking in model 1 (adjusted OR (aOR) 1.24, 95\% CI 1.05 to 1.46 ) and had marginally higher OR in model 2 (aOR $1.09,95 \%$ CI 0.92 to 1.30 ). The ORs of alcohol consumption and physical inactivity were not statistically significant in the with and without diabetes groups, although aOR for insufficient physical activity in the diabetes group was 1.16 (95\% CI 1.02 to 1.32 ) in model 1, and aOR 1.09 (95\% CI 0.95 to 1.24) in model 2. Compared with the unaware diabetes group, the aware diabetes group did not have any significant aORs in smoking, alcohol use and insufficient physical activity, but had lower OR (aOR 0.66, 95\% CI 0.45 to 0.99 ) in physical inactivity. Table 3 displays differences in preventive healthcare utilisation. Compared with the participants without diabetes, participants in the diabetes group had lower odds of receiving screening for cervical cancer (aOR $0.72,95 \%$ CI 0.60 to 0.86 ), breast cancer (aOR 0.80, $95 \%$ CI 0.65 to 0.98 ), gastric cancer (aOR $0.81,95 \%$ CI 0.70 to 0.93 ) and colon cancer (aOR $0.86,95 \%$ CI 0.75 to 0.99 ) as well as lower odds of receiving regular health check-ups within the past 2 years (aOR $0.75,95 \%$ CI 0.66 to 0.85$)$. Compared with the unaware diabetes group, participants in the aware diabetes group did not have significant ORs except for colon cancer screening (aOR $1.55,95 \%$ CI 1.17 to 2.05 ) and had marginally higher OR for gastric cancer screening (aOR 1.22, 95\% CI 0.93 to $1.60)$ in model 2.

Among participants aged $\geq 50$ years, the diabetes group had marginally greater odds of receiving an influenza vaccination (aOR $1.14,95 \% \mathrm{CI} 0.97$ to 1.34 ), and the aware diabetes group had higher odds compared with participants in the unaware group (aOR 1.56, 95\% CI 1.15 to 2.11) in model 2. As for psychosocial problems, we found there were higher odds of depressive symptom, suicidal thought and suicidal attempt between the diabetes group and non-diabetes group and between the unaware and aware diabetes groups in unadjusted or model 1, as shown in table 4. However, the significances were disappeared after adjusting confounding factors in model 2.

\section{DISCUSSION}

In this study, by using a nationally representative household survey, we showed that people with diabetes do not exhibit better health behaviours and were less likely to use preventive healthcare methods compared with those without diabetes, and in fact, awareness of their diabetes does not have a positive effect on health behaviours.

Our analyses yielded that smoking behaviour was slightly worse among patients with diabetes. Some previous studies have examined the smoking tendencies of patients with diabetes. MacFarlane, for instance, showed that patients with diabetes do not have different smoking habits from people without diabetes, and that $31 \%$ of patients with diabetes were current smokers. ${ }^{15}$ Gill et al also showed that smoking is common in patients with diabetes, with the smoking rates among black South African and British patients with diabetes being 20\% and $35 \%$, respectively. ${ }^{16}$ There are likely several explanations for people with diabetes having difficulty with smoking cessation. First, they must live a rather restricted lifestyle by following a specific diet, engaging in regular exercise and taking medication, which all may lead to cigarette cravings. ${ }^{15}$ Second, nicotine withdrawal causes a desire for sweet foods, which can in turn lead to stress among individuals with diabetes. Third, there is a close association between smoking and mental illness, and people in the diabetes group of our study showed a higher rate of suicidal thoughts than people in the no diabetes group, which may be one of the causes of the higher smoking rate observed in the diabetes group. ${ }^{26}$ 
Table 1 Characteristics of participants according to diabetes diagnosis and its awareness

\begin{tabular}{|c|c|c|c|}
\hline & $\begin{array}{l}\text { Without diabetes } \\
\mathrm{n}=12 \mathrm{750}(87.0 \%)\end{array}$ & $\begin{array}{l}\text { With diabetes, unaware } \\
\mathrm{n}=612(4.2 \%)\end{array}$ & $\begin{array}{l}\text { With diabetes, aware } \\
n=1293(8.8 \%)\end{array}$ \\
\hline \multicolumn{4}{|l|}{ Age, years } \\
\hline 30-39 & $3042(23.9)$ & $57(9.3)$ & $24(1.9)$ \\
\hline $40-64$ & $6892(54.1)$ & $329(53.8)$ & $593(45.9)$ \\
\hline $65-$ & $2816(22.1)$ & $226(36.9)$ & $676(52.3)$ \\
\hline \multicolumn{4}{|l|}{ Gender } \\
\hline Male & $5312(41.7)$ & $304(49.7)$ & $656(50.7)$ \\
\hline Female & $7438(58.3)$ & $308(50.3)$ & $637(49.3)$ \\
\hline \multicolumn{4}{|l|}{ Body mass index $\left(\mathrm{kg} / \mathrm{m}^{2}\right)$} \\
\hline$<18.5$ & $451(3.5)$ & $3(0.5)$ & $22(1.7)$ \\
\hline $18.5-24.9$ & $8315(65.4)$ & 259 (42.3) & $703(54.6)$ \\
\hline$>25$ & $3952(31.1)$ & $350(57.2)$ & $563(43.7)$ \\
\hline Fasting blood glucose (mg/dL) & $93.2 \pm 0.1$ & $140.3 \pm 2.3$ & $140.2 \pm 1.6$ \\
\hline $\mathrm{HbA1c}(\%)$ & $5.5 \pm 0.01$ & $7.2 \pm 0.1$ & $7.4 \pm 0.1$ \\
\hline \multicolumn{4}{|l|}{ Education level } \\
\hline Middle school or lower & $4676(36.7)$ & $350(57.4)$ & $821(63.5)$ \\
\hline High school & $4076(32.0)$ & $160(26.2)$ & $307(23.8)$ \\
\hline College or higher & $3980(31.3)$ & $100(16.4)$ & $164(12.7)$ \\
\hline \multicolumn{4}{|l|}{ Employment status } \\
\hline Non-manual & $4274(33.6)$ & $143(23.5)$ & $228(17.7)$ \\
\hline Manual & $3603(28.4)$ & $198(32.5)$ & $362(28.1)$ \\
\hline Others* & $4829(38.0)$ & $268(44.0)$ & $699(54.2)$ \\
\hline \multicolumn{4}{|l|}{ Marital status } \\
\hline Married & $12103(95.0)$ & $594(97.2)$ & $1272(98.5)$ \\
\hline Others† & $643(5.0)$ & $17(2.8)$ & $20(1.5)$ \\
\hline \multicolumn{4}{|l|}{ Household income } \\
\hline Low & $2252(17.8)$ & $170(28.4)$ & $445(34.7)$ \\
\hline Low middle & $3282(26.0)$ & $155(25.9)$ & $330(25.7)$ \\
\hline Middle high & $3497(27.7)$ & $149(24.9)$ & $262(20.4)$ \\
\hline High & $3590(28.4)$ & 125 (20.9) & $246(19.2)$ \\
\hline \multicolumn{4}{|l|}{ Smoking status } \\
\hline Past smoker/never & $10225(80.4)$ & 473 (77.9) & $1028(79.8)$ \\
\hline Current smoker & 2500 (19.6) & $134(22.0)$ & 261 (20.2) \\
\hline \multicolumn{4}{|l|}{ Alcohol use } \\
\hline Non-drinker & $7339(57.7)$ & $369(60.7)$ & $849(65.8)$ \\
\hline Drinker & $5383(42.3)$ & 239 (39.3) & $441(34.2)$ \\
\hline \multicolumn{4}{|l|}{ Physical activity } \\
\hline No & $1561(12.3)$ & $99(16.4)$ & $202(15.7)$ \\
\hline Insufficient & 5319 (41.9) & $252(41.8)$ & $485(37.7)$ \\
\hline Sufficient & $5821(45.8)$ & $252(41.8)$ & $601(46.7)$ \\
\hline
\end{tabular}

${ }^{*}$ Others include soldiers, students and housewives.

†Others include 'divorced', 'separated', 'widowed' and 'single'.

$\mathrm{HbA1c}$, haemoglobin A1c.

Our study revealed no differences in alcohol use between patients with diabetes and those without diabetes. Previous studies have similarly shown that people with diabetes do not exhibit better behaviour with regard to alcohol use. The study by Ahmed et alshowed that around $50.8 \%$ of people with diabetes in the USA were current 
Table 2 Differences in health-risk behaviours between groups according to diabetes diagnosis and its awareness

\begin{tabular}{|c|c|c|c|c|}
\hline & $\begin{array}{l}\text { Without diabetes } \\
n=12750(87.0 \%)\end{array}$ & $\begin{array}{l}\text { With diabetes } \\
n=1905(13.0 \%)\end{array}$ & $\begin{array}{l}\text { With diabetes, } \\
\text { unaware } \\
n=612(32.1 \%)\end{array}$ & $\begin{array}{l}\text { With diabetes, aware } \\
n=1293(67.9 \%)\end{array}$ \\
\hline \multicolumn{5}{|l|}{ Current smoking } \\
\hline Crude proportion, \% (total $n$ ) & $19.6(2500)$ & $20.8(395)$ & $22.1(134)$ & $20.2(261)$ \\
\hline Unadjusted OR (95\% Cl) & 1.00 & 1.01 (0.88 to 1.17$)$ & 1.00 & 0.87 (0.66 to 1.15$)$ \\
\hline Model 1 & 1.00 & 1.24 (1.05 to 1.46$)$ & 1.00 & $1.06(0.77$ to 1.48$)$ \\
\hline Model 2 & 1.00 & 1.09 (0.92 to 1.30$)$ & 1.00 & $1.04(0.74$ to 1.46$)$ \\
\hline \multicolumn{5}{|l|}{ Alcohol consumption* } \\
\hline Crude proportion, \% (total n) & $42.3(5383)$ & $35.8(680)$ & $39.3(239)$ & $34.1(441)$ \\
\hline Unadjusted OR (95\% Cl) & 1.00 & 0.75 (0.66 to 0.86$)$ & 1.00 & 0.73 (0.58 to 0.92$)$ \\
\hline Model 1 & 1.00 & 0.95 (0.82 to 1.10$)$ & 1.00 & 0.96 (0.72 to 1.30$)$ \\
\hline Model 2 & 1.00 & 0.95 (0.82 to 1.10$)$ & 1.00 & 0.97 (0.71 to 1.32$)$ \\
\hline \multicolumn{5}{|l|}{ Physical inactivity† } \\
\hline Crude proportion, \% (total n) & $47.7(5319)$ & $46.4(737)$ & $50.0(252)$ & $44.7(485)$ \\
\hline \multicolumn{5}{|l|}{ No physical activity } \\
\hline Unadjusted OR (95\% Cl) & 1.00 & 1.37 (1.16 to 1.63$)$ & 1.00 & 0.81 (0.57 to 1.16$)$ \\
\hline Model 1 & 1.00 & 1.16 (0.97 to 1.39$)$ & 1.00 & 0.67 (0.46 to 0.97 ) \\
\hline Model 2 & 1.00 & 1.02 (0.85 to 1.23$)$ & 1.00 & $0.66(0.45$ to 0.99$)$ \\
\hline \multicolumn{5}{|l|}{ Insufficient physical activity } \\
\hline Unadjusted OR (95\% Cl) & 1.00 & 1.07 (0.94 to 1.22$)$ & 1.00 & 0.85 (0.65 to 1.1$)$ \\
\hline Model 1 & 1.00 & 1.16 (1.02 to 1.32$)$ & 1.00 & 0.91 (0.70 to 1.20$)$ \\
\hline Model 2 & 1.00 & 1.09 (0.95 to 1.24$)$ & 1.00 & 0.88 (0.66 to 1.16$)$ \\
\hline
\end{tabular}

Model 1: adjusted using multiple logistic regression to control for age, gender and body mass index.

Model 2: adjusted using multiple logistic regression to control for age, gender, body mass index, education level, employment status, insurance status, household income and self-health status.

${ }^{*}$ Alcohol consumption was assessed according to the amount of drinking (Drinking more than two drinks for men and one drink for women). †Physical inactivity was assessed with the questionnaire based on International Physical Activity Questionnaire (IPAQ) short form. No physical activity: not participating in any combination of walking, moderate-intensity or vigorous-intensity activities in past week. Insufficient physical activity: some activity is reported but not enough to meet categories 2 (moderate) or 3 (high) of physical activity levels in the IPAQ short form analysis algorithm. Category 2: 3 or more days of vigorous activity of at least $20 \mathrm{~min} /$ day, or 5 or more days of moderate-intensity activity and/or walking of at least $30 \mathrm{~min} /$ day, or 5 or more days of any combination of walking, moderate-intensity or vigorous-intensity activities achieving a minimum of at least 600 metabolic equivalent task-min/week.

alcohol consumers, and that alcohol consumption was associated with poor compliance with diabetes self-care behaviours. ${ }^{27}$ Chew et al showed that around $30 \%$ of a sample of patients with diabetes in the USA were more than moderate alcohol drinkers, and these individuals tended to have poorer diabetes control compared with non-drinking patients. ${ }^{8}$

Our study demonstrated lower rates of physical inactivity in patients with diabetes awareness, and slightly higher rates of insufficient physical activity in patients with diabetes. Ranasinghe et al showed that the rate of physical inactivity among patients with diabetes in Sri Lanka was $13.9 \%$, which indicated that a significant proportion of adults with diabetes were sedentary. ${ }^{28}$ Palakodeti et al found that depression was an independent factor related to physical inactivity in patients with diabetes, while lifestyle counselling was found to be positively related to physical activity in the same group. ${ }^{29}$ Education on the proper amount of exercise and regular monitoring and feedback systems are needed to patients with diabetes to establish healthy diabetes management programmes with lifestyle modification.

Another key finding was that people with diabetes were less likely to use preventive healthcare methods compared with people without diabetes. Preventive healthcare is particularly important for preventing complications and comorbidities in people with chronic diseases such as diabetes. People who are aware of their diabetes typically visit a doctor every 3-6 months for their prescriptions and to check their glucose control in South Korea. Because these regular blood tests are performed by a doctor, patients may come to erroneously believe that they do not need regular health check-ups. Interestingly, the aware diabetes group had higher odds of colon cancer screening compared with the unaware group. Recently, many studies have been published about the link between diabetes and colon cancer incidence, ${ }^{30} 31$ which might induce people with diabetes to tend to get colonoscopies 
Table 3 Differences in cancer screening and other medical activities between groups according to diabetes diagnosis and its awareness

\begin{tabular}{|c|c|c|c|c|}
\hline Preventive healthcare utilisation & $\begin{array}{l}\text { Without diabetes } \\
\mathrm{n}=12750(87.0 \%)\end{array}$ & $\begin{array}{l}\text { With diabetes } \\
n=1905(13.0 \%)\end{array}$ & $\begin{array}{l}\text { With diabetes, } \\
\text { unaware } \\
\mathrm{n}=612(32.1 \%)\end{array}$ & $\begin{array}{l}\text { With diabetes, aware } \\
\mathrm{n}=1293(67.9 \%)\end{array}$ \\
\hline \multicolumn{5}{|l|}{$\begin{array}{l}\text { Cervical cancer screening* } \\
(\text { age } \geq 30)\end{array}$} \\
\hline Crude proportion, \% (total n) & $76.5(5682)$ & $64.3(606)$ & $65.1(200)$ & $63.9(406)$ \\
\hline Unadjusted OR (95\% Cl) & 1.00 & 0.58 (0.49 to 0.68$)$ & 1.00 & 0.84 (0.59 to 1.20$)$ \\
\hline Model 1 & 1.00 & 0.70 (0.59 to 0.84$)$ & 1.00 & 1.04 (0.72 to 1.51$)$ \\
\hline Model 2 & 1.00 & 0.72 (0.60 to 0.86$)$ & 1.00 & $1.04(0.84$ to 1.59$)$ \\
\hline
\end{tabular}

Breast cancer screening $\dagger$

(age $\geq 40$ )

\begin{tabular}{|lcccc|}
\hline Crude proportion, \% (total $\mathrm{n})$ & $81.3(4565)$ & $74.9(676)$ & $74.3(208)$ & $75.1(468)$ \\
\hline Unadjusted OR $(95 \% \mathrm{Cl})$ & 1.00 & $0.71(0.59$ to 0.86$)$ & 1.00 & $0.87(0.58$ to 1.30$)$ \\
\hline Model 1 & 1.00 & $0.80(0.65$ to 0.98$)$ & 1.00 & $1.03(0.66$ to 1.58$)$ \\
\hline Model 2 & 1.00 & $0.80(0.65$ to 0.98$)$ & 1.00 & $0.98(0.62$ to 1.54$)$ \\
$\begin{array}{l}\text { Gastric cancer screening } \\
\text { (age } \geq 40)\end{array}$ & & & \\
\hline Crude proportion, \% (total n) & $73.2(7103)$ & $67.7(1234)$ & $65.6(363)$ & $68.6(871)$ \\
\hline Unadjusted OR $(95 \% \mathrm{Cl})$ & 1.00 & $0.80(0.70$ to 0.91$)$ & 1.00 & $1.18(0.91$ to 1.53$)$ \\
\hline Model 1 & 1.00 & $0.78(0.68$ to 0.90$)$ & 1.00 & $1.20(0.92$ to 1.57$)$ \\
\hline Model 2 & 1.00 & $0.81(0.70$ to 0.93$)$ & 1.00 & $1.22(0.93$ to 1.60$)$ \\
\hline
\end{tabular}

Colon cancer screening§

(age $\geq 50$ )

\begin{tabular}{|c|c|c|c|c|}
\hline Crude proportion, \% (total n) & 58.1 (3992) & $52.6(859)$ & $47.4(215)$ & $54.6(644)$ \\
\hline Unadjusted OR (95\% Cl) & 1.00 & 0.84 (0.74 to 0.97$)$ & 1.00 & 1.40 (1.07 to 1.83$)$ \\
\hline Model 1 & 1.00 & 0.86 (0.75 to 0.99$)$ & 1.00 & 1.51 (1.14 to 1.99$)$ \\
\hline Model 2 & 1.00 & 0.86 (0.75 to 0.99$)$ & 1.00 & 1.55 (1.17 to 2.05 ) \\
\hline \multicolumn{5}{|l|}{$\begin{array}{l}\text { Health screening recent } 2 \text { years } \\
(\text { age } \geq 30)\end{array}$} \\
\hline Crude proportion, \% (total n) & $63.8(8132)$ & $61.9(1178)$ & $60.4(369)$ & $62.6(809)$ \\
\hline Unadjusted OR (95\% CI) & 1.00 & 0.93 (0.82 to 1.05$)$ & 1.00 & $1.18(0.90$ to 1.54$)$ \\
\hline Model 1 & 1.00 & 0.71 (0.63 to 0.81$)$ & 1.00 & 1.16 (0.88 to 1.54$)$ \\
\hline Model 2 & 1.00 & 0.75 (0.66 to 0.85$)$ & 1.00 & 1.17 (0.88 to 1.57$)$ \\
\hline \multicolumn{5}{|l|}{ Influenza vaccination (age $\geq 50$ ) } \\
\hline Crude proportion, \% (total n) & $51.7(3553)$ & $62.5(1020)$ & $53.4(243)$ & $66.1(777)$ \\
\hline Unadjusted OR (95\% Cl) & 1.00 & 1.52 (1.32 to 1.74$)$ & 1.00 & 1.77 (1.36 to 2.30$)$ \\
\hline Model 1 & 1.00 & 1.19 (1.01 to 1.39$)$ & 1.00 & 1.72 (1.29 to 2.30$)$ \\
\hline Model 2 & 1.00 & 1.14 (0.97 to 1.34$)$ & 1.00 & 1.56 (1.15 to 2.11$)$ \\
\hline
\end{tabular}

Model 1: adjusted using multiple logistic regression to control for age, gender and body mass index.

Model 2: adjusted using multiple logistic regression to control for age, gender, body mass index, education level, employment status,

insurance status, household income and self-health status.

${ }^{*}$ Receipt of a Papanicolaou test within the past 2 years among women with uterus.

tReceipt of a mammography or breast ultrasonography within the past 2 years among women with breast.

¥Receipt of a gastroduodenoscopy or double-contrast upper gastrointestinal series within the past 2 years.

§Receipt of a colonoscopy or sigmoidoscopy or barium enema within the past 5 years.

more by themselves or through doctors' recommendation. Further studies are needed to explain this association. We also found that influenza vaccinations were very frequently taken by patients who were aware. Influenza vaccinations are necessary preventative measures for patients with chronic diseases, including diabetes and older adults. ${ }^{12}$ Patients who are aware of their diabetes, in general, can easily obtain a doctor's recommendation for 
Table 4 Differences in mental health status according to diabetes diagnosis and its awareness

\begin{tabular}{|c|c|c|c|c|}
\hline Psychosocial problems & $\begin{array}{l}\text { Without diabetes } \\
\mathrm{n}=12750(87.0 \%)\end{array}$ & $\begin{array}{l}\text { With diabetes } \\
n=1905(13.0 \%)\end{array}$ & $\begin{array}{l}\text { With diabetes, } \\
\text { unaware } \\
n=612(32.1 \%)\end{array}$ & $\begin{array}{l}\text { With diabetes, aware } \\
\mathrm{n}=1293(67.9 \%)\end{array}$ \\
\hline \multicolumn{5}{|l|}{ Depressive symptom* } \\
\hline $\begin{array}{l}\text { Crude proportion, \% } \\
\text { (total n) }\end{array}$ & $12.9(1643)$ & $15.2(289)$ & $13.2(81)$ & $16.1(208)$ \\
\hline $\begin{array}{l}\text { Unadjusted OR } \\
(95 \% \mathrm{Cl})\end{array}$ & 1.00 & 1.23 (1.03 to 1.46$)$ & 1.00 & 1.43 (1.00 to 2.04$)$ \\
\hline Model 1 & 1.00 & 1.15 (0.96 to 1.38$)$ & 1.00 & 1.48 (1.03 to 2.14$)$ \\
\hline Model 2 & 1.00 & 0.94 (0.78 to 1.13 ) & 1.00 & 1.19 (0.82 to 1.73$)$ \\
\hline \multicolumn{5}{|l|}{ Suicidal thought $†$} \\
\hline $\begin{array}{l}\text { Crude proportion, \% } \\
\text { (total n) }\end{array}$ & $13.5(1720)$ & $17.7(336)$ & $16.4(100)$ & $18.3(236)$ \\
\hline $\begin{array}{l}\text { Unadjusted OR } \\
(95 \% \mathrm{Cl})\end{array}$ & 1.00 & 1.41 (1.18 to 1.67$)$ & 1.00 & 1.38 (1.01 to 1.87$)$ \\
\hline Model 1 & 1.00 & 1.21 (1.02 to 1.45$)$ & 1.00 & 1.28 (0.94 to 1.75$)$ \\
\hline Model 2 & 1.00 & 1.01 (0.85 to 1.21$)$ & 1.00 & 1.05 (0.75 to 1.48$)$ \\
\hline \multicolumn{5}{|l|}{ Suicidal attemptł } \\
\hline $\begin{array}{l}\text { Crude proportion, \% } \\
\text { (total n) }\end{array}$ & $4.2(72)$ & $5.7(19)$ & $5.0(5)$ & $5.9(14)$ \\
\hline $\begin{array}{l}\text { Unadjusted OR } \\
(95 \% \mathrm{Cl})\end{array}$ & 1.00 & 1.46 (1.24 to 1.73$)$ & 1.00 & 1.37 (1.01 to 1.87$)$ \\
\hline Model 1 & 1.00 & 1.22 (1.02 to 1.45$)$ & 1.00 & 1.27 (0.93 to 1.75$)$ \\
\hline Model 2 & 1.00 & 1.01 (0.85 to 1.21$)$ & 1.00 & 1.04 (0.74 to 1.47$)$ \\
\hline
\end{tabular}

Model 1: adjusted using multiple logistic regression to control for age, gender and body mass index.

Model 2: adjusted using multiple logistic regression to control for age, gender, body mass index, education level, employment status, insurance status, household income and self- health status.

*Felt sad, unhappy or desperate for more than 2 weeks, which interfered with the daily activities during the past year.

†Suicidal thought in the past year.

‡Suicidal attempt in the past year.

an influenza vaccination during regular visits to outpatient clinics, which might explain the higher rate of influenza vaccination in that group than in other groups.

The final key finding in this study was that patients with diabetes had no significant finding in mental health compared with non-diabetes group. Previous studies have demonstrated the association between mental health status and diabetes, suggested mechanisms for this association. Several studies have also shown that the prevalence of suicidal ideation among patients with diabetes was significantly higher than that among people without diabetes. ${ }^{20} 32$ Psychosocial problems can have detrimental effects on the healthy behaviours of patients with diabetes. ${ }^{21}$ Treatment methods for these psychosocial problems, such as a combination of psychosocial interventions and pharmacological treatment, might, therefore, improve mental health and the self-care behaviours of people with diabetes. ${ }^{33}$ Further studies are needed to evaluate of mental health status in patients with diabetes and political and economic supports from the government could be considered to monitor the mental health of people with chronic disease in Korea.
This study has several limitations. First, this study was based on a cross-sectional survey, which precluded the identification of causality. Therefore, the association between diabetes and healthy preventive behaviour has difficulties in interpreting the cause and result. Additional prospective studies are needed to determine the causal effects of diabetes on health-related variables. Second, it is possible that this sample had a disproportionate number of patients with relatively mild diabetes because people admitted to a hospital or nursing home were not included in the KNHANES, and we could not measure the severity or type of diabetes, which are closely related to health-risk behaviours, preventive healthcare utilisation and mental health status. Future studies should explore these associations using more sophisticated data. Third, our study used self-administered questionnaires to obtain most of the information, which may be subject to recall bias. Fourth, screening participation can be affected by various factors in numerous domains (including personal, familial, social, organisational and cultural). Thus, there might have been confounding factors that we did not consider in our analysis. Despite 
the limitations, this is, to our knowledge, the first study to examine how health-related factors differ according to diabetes diagnosis and awareness of that diagnosis in a nationally representative population.

In conclusion, we demonstrated that people with diabetes do not exhibit better health-related behaviours or preventive healthcare management. More studies are needed to identify the causality of health behaviour, preventive health utilisation and mental health with diabetes and further efforts and political attention to ensuring the quality of care for people with diabetes are needed. This would be helpful for managing diabetes and for ensuring that these individuals continue leading a healthy life without complications or comorbidities.

Contributors H-YS and SMP made substantial contributions to the conception, design and development of methodology. H-YS and SP collected and analysed data. SMP interpreted the data. H-YS wrote the manuscript and SMP and H-YS reviewed and revised the manuscript together. $\mathrm{H}-\mathrm{YS}$ and SP were responsible for administrative, technical and material support, and SMP supervised all phases of the study.

Funding This research received no specific grant from any funding agency in the public, commercial or not-for-profit sectors.

Competing interests None declared.

Patient consent Obtained.

Ethics approval The Institutional Review Board of the Korea Centers for Disease Control and Prevention approved this study.

Provenance and peer review Not commissioned; externally peer reviewed.

Data sharing statement № additional data are available.

Open access This is an open access article distributed in accordance with the Creative Commons Attribution Non Commercial (CC BY-NC 4.0) license, which permits others to distribute, remix, adapt, build upon this work non-commercially, and license their derivative works on different terms, provided the original work is properly cited and the use is non-commercial. See: http://creativecommons.org/ licenses/by-nc/4.0/

(C) Article author(s) (or their employer(s) unless otherwise stated in the text of the article) 2018. All rights reserved. No commercial use is permitted unless otherwise expressly granted.

\section{REFERENCES}

1. World Health Organization. Noncommunicable diseases. http://www. who.int/mediacentre/factsheets/fs355/en/ (accessed 13 Jan 2017).

2. Korean Diabetes Association. Korean diabetes fact sheet. National health insurance service. 2015 http://www.diabetes.or.kr/temp/KDA fact sheet\%202015.pdf (accessed 13 Jan 2017).

3. Kim HC, Oh SM. Noncommunicable diseases: current status of major modifiable risk factors in Korea. J Prev Med Public Health 2013;46:165-72.

4. Jee SH, Foong AW, Hur NW, et al. Smoking and risk for diabetes incidence and mortality in Korean men and women. Diabetes Care 2010;33:2567-72.

5. American Diabetes Association. (4) Foundations of care: education nutrition, physical activity, smoking cessation, psychosocial care, and immunization. Diabetes Care 2015;38 Suppl:S20-30.

6. Buse JB, Ginsberg HN, Bakris GL, et al. Primary prevention of cardiovascular diseases in people with diabetes mellitus: a scientific statement from the American Heart Association and the American Diabetes Association. Circulation 2007;115:114-26.

7. Anthonisen NR, Skeans MA, Wise RA, et al. The effects of a smoking cessation intervention on 14.5-year mortality: a randomized clinical trial. Ann Intern Med 2005;142:233-9.

8. Chew LD, Nelson KM, Young BA, et al. Association between alcohol consumption and diabetes preventive practices. Fam Med 2005;37:589-94.

9. Turner BC, Jenkins E, Kerr D, et al. The effect of evening alcohol consumption on next-morning glucose control in type 1 diabetes. Diabetes Care 2001;24:1888-93.
10. Richardson $\mathrm{T}$, Weiss $\mathrm{M}$, Thomas $\mathrm{P}$, et al. Day after the night before: influence of evening alcohol on risk of hypoglycemia in patients with type 1 diabetes. Diabetes Care 2005;28:1801-2.

11. Tanasescu M, Leitzmann MF, Rimm EB, et al. Physical activity in relation to cardiovascular disease and total mortality among men with type 2 diabetes. Circulation 2003;107:2435-9.

12. Korean Diabetes Association. Treatment guideline for diabetes. http://www.diabetes.or.kr/bbs/index.html?code=e_resource\&mode= tlist.

13. Ministry of health and welfare. http://www.mohw.go.kr/eng/index.jsp (accessed 13 Jan 2017).

14. Complication of diabetes. International diabetes federation. http:// www.idf.org/complications-diabetes (accessed 13 Jan 2017).

15. MacFarlane IA. The smoker with diabetes: a difficult challenge. Postgrad Med J 1991;67:928-30.

16. Gill GV, Rolfe M, MacFarlane IA, et al. Smoking habits of black South African patients with diabetes mellitus. Diabet Med 1996;13:996-9.

17. Chung JH, Kim OS. Alcohol consumption and cigarette smoking in men with diabetes mellitus. J Korean Acad Adult Nurs 2005;17:68-76.

18. Chen S, Zhang Q, Dai G, et al. Association of depression with prediabetes, undiagnosed diabetes, and previously diagnosed diabetes: a meta-analysis. Endocrine 2016;53:35-46.

19. Chung JH, Moon K, Kim DH, et al. Suicidal ideation and suicide attempts among diabetes mellitus: the Korea National Health and Nutrition Examination Survey (KNHANES IV, V) from 2007 to 2012. J Psychosom Res 2014;77:457-61.

20. Sarkar S, Balhara YP. Diabetes mellitus and suicide. Indian J Endocrinol Metab 2014;18:468-74.

21. Smith KJ, Pedneault M, Schmitz N. Investigation of anxiety and depression symptom co-morbidity in a community sample with type 2 diabetes: associations with indicators of self-care. Can J Public Health 2016;106:e496-501.

22. International Physical Activity Questionnaire. Guidelines for data processing and analysis of the International Physical Activity Questionnaire (IPAQ): short and long forms. https://www.google. co.kr/url?sa $=\mathrm{t} \& \mathrm{rct}=\mathrm{j} \& \mathrm{q}=\&$ esrc $=\mathrm{s} \&$ source $=$ web\& $\mathrm{cd}=2 \& \mathrm{ved}=0 \mathrm{ahU}$ KEwiny9W2lbzMAhVI5aYKHVC- CjoQFggnMAE\&url=https\% 3A\%2F\%2Fwww.researchgate.net\%2Ffile.PostFileLoader. html\%3Fid\%3D56f92d66615e27d49a658031\%26assetKey\% 3DAS\%253A344600888791041\%25401459170662924\&usg= AFQjCNFu86dTe OuPWO-puYIPhGnZbyAhw\&sig2=m82MYoYliqzXP4AJpB2_A\&bvm=bv.121070826,d.dGY (accessed 13 Jan 2017).

23. Pate RR, Pratt M, Blair SN, et al. Physical activity and public health. A recommendation from the centers for disease control and prevention and the American college of sports medicine. JAMA 1995;273:402-7.

24. Cho J, Guallar E, Hsu YJ, et al. A comparison of cancer screening practices in cancer survivors and in the general population: the Korean national health and nutrition examination survey (KNHANES) 2001-2007. Cancer Causes Control 2010;21:2203-12.

25. Kim Y, Jun JK, Choi KS, et al. Overview of the national cancer screening programme and the cancer screening status in Korea. Asian Pac J Cancer Prev 2011:12:725-30.

26. Genuth $S$, Alberti KG, Bennett P, et al. Follow-up report on the diagnosis of diabetes mellitus. Diabetes Care 2003;26:3160-7.

27. Ahmed AT, Karter AJ, Liu J. Alcohol consumption is inversely associated with adherence to diabetes self-care behaviours. Diabet Med 2006;23:795-802.

28. Ranasinghe DC, Ranasinghe $P$, Jayawardena R, et al. Evaluation of physical activity among adults with diabetes mellitus from Sri Lanka. Int Arch Med 2014;7:15.

29. Palakodeti S, Uratsu CS, Schmittdiel JA, et al. Changes in physical activity among adults with diabetes: a longitudinal cohort study of inactive patients with type 2 diabetes who become physically active. Diabet Med 2015;32:1051-7.

30. Jee $\mathrm{SH}$, Ohrr H, Sull JW, et al. Fasting serum glucose level and cancer risk in Korean men and women. JAMA 2005;293:194-202.

31. Shin HY, Jung KJ, Linton JA, et al. Association between fasting serum glucose levels and incidence of colorectal cancer in Korean men: the Korean cancer prevention study-II. Metabolism 2014;63:1250-6.

32. Joshi P, Song HB, Lee SA. Association of chronic disease prevalence and quality of life with suicide-related ideation and suicide attempt among Korean adults. Indian J Psychiatry 2017;59:352-8.

33. Kok JL, Williams A, Zhao L. Psychosocial interventions for people with diabetes and co-morbid depression. A systematic review. Int J Nurs Stud 2015:52:1625-39. 